\title{
Asistencia personal: equiparación de derechos y oportunidades. Comparativa entre Suecia y España
}

\author{
Personal assistance: equality of rights and opportunities. Comparison \\ between Sweden and Spain
}

\begin{abstract}
Resumen
Con el nacimiento y desarrollo del Movimiento de Vida Independiente, las personas con diversidad funcional tomaron conciencia de sus derechos como ciudadanos. Uno de estos es el derecho a vivir de forma independiente y a ser incluido en la comunidad y para hacerlo realidad es fundamental la asistencia personal. Con la llegada de este movimiento a Europa, y gracias a sus demandas, se han puesto en marcha diferentes iniciativas de asistencia personal y se han aprobado normativas nacionales que la regulan. En este artículo se analizan las políticas públicas sobre asistencia personal que se están implementando en Suecia y su comparación con las existentes en nuestro país.
\end{abstract}

\section{Palabras claves}

Movimiento de vida independiente, asistencia personal, pago directo, autogestión, asistente personal.

\begin{abstract}
From the beginning and development of the Independent Living Movement, people with functional diversity became aware of their rights as citizens. One of these is the right to live independently and to be included in the community. To make it real, personal assistance is fundamental. With the arrival of this movement to Europe and thanks to its demands, different personal assistance initiatives have been launched and national regulations to regulate this resource have been approved. In this article we analyse the public policies on personal assistance that are being implemented in Sweden and their comparison with those existing in our country.
\end{abstract}

\section{Keywords}

Independent living movement, personal assistance, direct payment, self-management, personal assistant.

\author{
Mercedes López Pérez \\ $<$ mlp00004@red.ujaen.es> \\ Universidad de Jaén. España
}

\section{Susana Ruiz Seisdedos} <suruiz@ujaen.es>

Universidad de Jaén. España

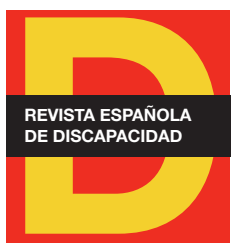

Para citar:

López, M. y Ruiz, S. (2018):

"Asistencia personal: equiparación de derechos y oportunidades. Comparativa entre Suecia y España". Revista Española de Discapacidad, 6 (II): 103-130.

Doi: <https://doi.org/10.5569/23405104.06.02.06>

Fecha de recepción: 15-03-2017 Fecha de aceptación: 02-05-2018 


\section{Introducción}

La diversidad funcional ${ }^{1}$ es un fenómeno tan antiguo como la humanidad. Siempre han existido personas con algunas características físicas, psíquicas y/o sensoriales como consecuencia de una malformación, enfermedad o accidente que veían limitado su desarrollo personal, su autonomía y su inclusión en la sociedad. A lo largo de los siglos estas personas, en el mejor de los casos, han sido aisladas y relegadas a la marginalidad, la indigencia, el desprecio y la exclusión. En el peor de los casos, se consideraba que sus vidas no merecían la pena ser vividas por lo que eran condenadas a morir (Aguado, 1995).

El fenómeno de la discapacidad ${ }^{2}$ engloba a un grupo de personas muy heterogéneo, ya sea por el origen, tipo y grado de esta, por la edad, por la cultura, etc. Sin embargo, todas tienen en común su experiencia con la discriminación, tienen que enfrentarse a múltiples barreras que les impiden participar en su comunidad, lo que les supone un gran riesgo de caer en la exclusión y en la pobreza (CERMI, 2003). La sociedad ve la discapacidad como algo negativo, se asocia al sufrimiento y a la enfermedad, por ello hay que curarla para que puedan ser personas "normales" y se adapten a un rol determinado. En la mayoría de los casos, estas personas no pueden decidir sobre cuestiones que les afectan directamente como su proceso de recuperación, dónde y con quién vivir, cuando levantarse o acostarse, etc. (Palacios y Romañach, 2006).

Afortunadamente, esta situación ha ido cambiando y el enfoque sobre el mundo de la discapacidad ha evolucionado hacia una cuestión de derechos que afecta a toda la sociedad. Ha sido sobre todo, a partir de la segunda mitad del siglo XX, cuando estas personas han salido y han reivindicado su lugar en la sociedad, en una situación de igualdad y ciudadanía (Hyung Shik, 2010; Palacios y Romañach, 2006).

Una consecuencia de esta concienciación ha sido la aprobación, años más tarde, de las primeras normativas internacionales, europeas y nacionales referentes a los derechos de estas personas. Entre ellas, destacar la Convención de las Naciones Unidas sobre los Derechos de las Personas con Discapacidad que, en su artículo $19^{3}$, reconoce el derecho a vivir de forma independiente, en su propia comunidad y en igualdad de condiciones con el resto de la población. Para hacerlo realidad, reconoce el acceso a una variedad de servicios, entre ellos la asistencia personal, como herramienta clave para facilitar su inclusión social y evitar su aislamiento (ONU, 2006).

\footnotetext{
1. Es un concepto novedoso que surge en España en 2005 a propuesta del Foro de Vida Independiente y Divertad, como alternativa a los utilizados hasta el momento. Por primera vez se utiliza un término en positivo para referirse a las personas con deficiencias que tienen limitados sus derechos y la participación en su entorno por dichas causas y pone la atención en la diferencia como valor enriquecedor para la sociedad (Romañach y Lobato, 2005; Toboso, 2010).

2. Según la Clasificación Internacional de las Deficiencias, Discapacidades y Minusvalías, la discapacidad es toda restricción o ausencia de la capacidad de realizar una actividad en la forma o dentro del margen que se considera normal para un ser humano (OMS, 1980). Por otro lado, la Clasificación Internacional del Funcionamiento, de la Discapacidad y la Salud la considera como la consecuencia de la relación entre la condición de salud de una persona, sus factores personales y sus factores ambientales (OMS, 2001).

3. En octubre del 2017, el Comité sobre Derechos de las Personas con Discapacidad publicó la Observación general núm. 5 (2017) sobre el derecho a vivir de forma independiente y a ser incluido en la comunidad, en la cual se analiza la situación actual de este derecho (ONU, 2017).
} 


\section{Movimiento de Vida Independiente}

En una sociedad como la nuestra, todo está interrelacionado, nadie es autosuficiente y todos necesitamos de alguien o de algo a lo largo de nuestra vida. Sin embargo, esta situación, que es obvia para la mayoría de las personas, es un motivo de exclusión para una parte de la población, concretamente para todas aquellas personas que por su diversidad funcional no pueden realizar algunas de las actividades cotidianas. Esto hace que el derecho a vivir de forma independiente se convierta en una quimera. En oposición a esta situación de marginalidad y exclusión nace el Independent Living Movement (Movimiento de Vida Independiente) que defiende que la inclusión de las personas con diversidad funcional en la sociedad solo es posible si son consideradas portadoras de derechos. Así se inicia el camino para entender la diversidad funcional como una cuestión de derechos (Arnau, 2002).

\subsection{Orígenes y desarrollo del Movimiento de Vida Independiente}

Este movimiento surge en los Estados Unidos de América a finales de los 60 y principio de los 70 del siglo $X X$. Este periodo se caracterizó por ser una época de constantes revueltas y reivindicaciones de todo tipo que supusieron el auge de diferentes movimientos políticos y sociales, como el movimiento por la lucha por los derechos civiles, políticos y humanos de las personas afro-americanas, el movimiento por los derechos de las mujeres, etc. En este contexto histórico, son las propias personas con diversidad funcional las que se agruparon para reivindicar sus derechos y libertades bajo el lema Nothing about us, without us (Nada sobre nosotros, sin nosotros). El Movimiento de Vida Independiente reclama el derecho a la vida independiente de todas las personas con diversidad funcional, con los apoyos que sean necesarios (Arnau, 2013; García Alonso, 2003; láñez, 2009; Madrid, 2013) y fue determinante para lograr importantes avances, transformando las limitaciones en derechos y bienestar de esta población (Nóvoa, 2003; Power, 2013). También se caracteriza por redefinir el fenómeno de la discapacidad, lo que dio lugar a nuevos modelos de servicios y prestaciones (Dejong, 1979a).

Ed Roberts es considerado como "el padre" de este movimiento (Campo, 2005; Dejong, 1979a; García Vidal, 2003; láñez, 2009). Fue la primera persona con gran diversidad funcional y grandes necesidades de apoyo, admitida como estudiante en la Universidad de Berkeley (California). Años más tarde se asoció con otros estudiantes con diversidad funcional de dicha universidad para crear el Physically disabled student's program (Programa de estudiantes discapacitados físicos), iniciándose así el desarrollo del Movimiento de Vida Independiente (Palacios y Romañach, 2006; Urmeneta, 2007). Con este programa demandaron mejoras en el campus universitario, como mayor accesibilidad, transporte adaptado, talleres para reparar las ayudas técnicas y, por supuesto, un servicio de asistencia personal (Campo, 2005). Dos años después, este grupo fundó el primer Center for independent living (Centro de vida independiente), en la misma Universidad. Posteriormente se crearon otros fuera de la universidad, comenzando la expansión por todo el territorio estadounidense, fundándose en California, Houston, Boston, New York y Chicago (García Alonso, 2003). 


\subsection{Filosofía del Movimiento de Vida Independiente}

El Movimiento de Vida Independiente se asienta en una corriente filosófica internacional que define la diversidad funcional, delimita el problema que pueda significar, busca las soluciones a ese posible problema y señala a los responsables para dar soluciones. Considera que es el entorno socio-político, económico, arquitectónico y de comunicación el que discapacita. Por lo cual, la reivindicación de los derechos humanos por parte de las personas con diversidad funcional, es la forma de abandonar la situación de discriminación en que viven (Arnau, 2006; García Alonso, 2003). Irreversiblemente, esta filosofía origina una voluntad de cambio en las políticas y en la legislación que favorece una actitud nueva frente al fenómeno de la diversidad funcional (Maraña y Ratzka, 1999). Inspirada en los principios del empowerment, parte de la idea de que todas las personas tienen derecho a la independencia a través del máximo control sobre sus vidas, basado en la capacidad y la oportunidad para tomar decisiones y de llevar a cabo las actividades de cada día (láñez, 2009; Niesz et al, 2008). Entre sus principios básicos y universales están (García Alonso, 2004; láñez, 2009; Lobato, 2005; Maraña y Lobato, 2003):

- Garantizar los derechos humanos y civiles;

- Autocontrol;

- Autodeterminación de las personas para decidir su propio destino;

- Autoayuda o apoyo entre iguales;

- Igualdad de oportunidades;

- Posibilidad para ejercer poder (empoderamiento);

- Derecho a asumir riesgos;

- No discriminación;

- $\quad$ Calidad de vida.

Estos se emplean con independencia del tipo de diversidad funcional, edad, sexo u orientación sexual, raza, religión, etc. que tenga la persona (Arnau, 2006). A su vez, estos principios se fundamentan en cuatros pilares (Deegan, 1992; Morris, 1993; Niesz et al., 2008; Planella et al., 2012):

1. Toda vida humana tiene un valor;

2. Todas las personas, cualquiera que sea su deficiencia, son capaces de realizar elecciones;

3. Las personas con diversidad funcional lo son por la respuesta de la sociedad a la deficiencia física, intelectual y/o sensorial;

4. Éstas tienen derecho a ejercer el control de sus vidas y a la plena participación en la sociedad;

Para alcanzarlos y conseguir las condiciones necesarias para una vida independiente, este movimiento demanda (Arnau, 2006; Centeno et al., 2008; Urmeneta, 2011):

- Un servicio de asistencia personal auto-gestionado, eficaz y asequible a la economía de cada persona; 
- $\quad$ Ayudas económicas en forma de pago directo;

- La accesibilidad del entorno y ayudas técnicas para lograr una verdadera autodeterminación;

- Una educación inclusiva que posibilite un desarrollo personal y social;

- $\quad$ El derecho a vivir su propia sexualidad y a poder formar una familia.

Esta filosofía surgió en oposición al modelo hegemónico hasta ese momento, el médico-rehabilitador, (Arnau, 2006; Planella et al., 2012; White et al., 2010) a través de tres ideas: des-institucionalización, desmedicalización y des-profesionalización. Desde este nuevo enfoque, las personas con diversidad funcional tienen un papel activo y participativo en la sociedad, en contraposición a la tradicional imagen "pasiva" o paciente que se les ha dado en el modelo médico-rehabilitador (Dejong, 1979b; Madrid, 2013; Palacios y Romañach, 2006).

Aquí el concepto de vida independiente se considera un manifiesto a favor de la normalización, la autodeterminación y la autorrealización de las personas con diversidad funcional. Implica proporcionar los apoyos que sean necesarios a estas personas para que, cualquiera que sea su deficiencia, puedan ejercer su derecho de elección. Según Gómez (2012) este movimiento redefine el concepto de vida independiente y, para ello, realiza una revisión del concepto de vida y asume que todo tipo de vida posee un valor intrínseco e igual en dignidad. Además, estudia los diferentes aspectos que impiden el acceso a los derechos humanos de las personas con diversidad funcional y reconoce el derecho a poder elegir su modo de vida, independientemente de su nivel de autonomía (Niesz et al., 2008). En definitiva, la vida independiente es lo que la mayoría de las personas sin diversidad funcional dan por hecho, vivir la vida que quieren vivir, decidir lo que quieren hacer y luego, tener la oportunidad y el apoyo para hacerlo (García Alonso, 2003; Gillinson et al., 2005). Por lo que el objetivo de cualquier política y/o servicio debería ser empoderar a las personas con diversidad funcional para superar las barreras que les impiden asumir el rol de ciudadano (Zarb, 2003) y la asistencia personal es un servicio de apoyo esencial para esta finalidad, especialmente los sistemas de pago directo (Zarb y Nadash, 1994).

En definitiva, la filosofía de vida independiente se basa en un movimiento de personas que reclaman sus derechos sin intermediarios, en cooperación y ayuda mutua (Gómez, 2012). Como afirmara John Evans (1998) en la Conferencia sobre Vida Independiente de Londres: "La esencia de la vida independiente es la libertad de tomar decisiones sobre tu propia vida y de participar plenamente en tu comunidad". Por lo que la autonomía se convierte en una necesidad (Doyal y Gough, 1991; Maslow, 1943) y en un derecho para alcanzar un bienestar y una calidad de vida (Boyle, 2008), convirtiendo así, el servicio de asistencia personal en una pieza clave para conseguirlo.

\subsection{Llegada y expansión del Movimiento de Vida Independiente en Europa}

Fue en la década de los años 80 cuando el Movimiento de Vida Independiente llega al continente europeo. Comienza introduciéndose por los países nórdicos y se extiende al resto del continente (Suecia, Reino Unido, Alemania, Italia, etc.). Años más tarde, como consecuencia de su expansión y desarrollo, se fueron aprobando normativas específicas sobre asistencia personal y vida independiente en países como Suecia, Reino Unido, Italia y Noruega (Campo, 2005). 
Los precursores del Movimiento de Vida Independiente europeo fueron personas que previamente se habían trasladado durante un tiempo a los Estado Unidos de América con objeto de aprender todo lo relacionado con este movimiento y poder implantarlo posteriormente en sus respectivos países. Se atribuye a John Evans en el Reino Unido y a Adolf Radzka en Suecia, los inicios en Europa (Rodríguez-Picavea, 2010). Gracias a ellos, las personas con diversidad funcional en este continente fueron tomando conciencia de sus derechos y se agruparon creando numerosos centros de vida independiente, cooperativas, plataformas, foros, etc. Años más tarde, se formaron diferentes organizaciones como la European Network of Independent Living (ENIL) o Red Europea de Vida Independiente, el European Disability Forum (EDF) o Foro Europeo de la Discapacidad, la European Coalition for Community Living (ECCL) o Coalición Europea para la Vida en Comunidad, etc. Por su parte, a nivel nacional también surgen diferentes iniciativas como el Independent Living Institute (ILI) o Instituto de Vida Independiente en Suecia y el Foro de Vida Independiente y Divertad (FVID) en nuestro país.

Si atendemos a la relación causa-efecto entre las reivindicaciones de este movimiento y el desarrollo de la asistencia personal en estos dos países, destacar que en Suecia solo hizo falta una década para conseguir que se reconociera la asistencia personal como un derecho de las personas con diversidad funcional. En el caso de España, esta relación causa-efecto no ha sido tan nítida, como veremos en los próximos apartados, la asistencia personal es un derecho desde el año 2006, sin embargo, su desarrollo es insuficiente.

En Suecia, la llegada de este movimiento se sitúa a finales de 1983, coincidiendo con la celebración de la Conferencia Internacional sobre el Movimiento de Vida Independiente celebrada en la ciudad de Estocolmo, en la que intervinieron Ed Roberts y Judy Heumann, como representantes del Movimiento de Vida Independiente de los EE.UU. En dicha conferencia se presentó la filosofía y el enfoque de este movimiento a los participantes que asistieron de Noruega, Dinamarca y de la propia Suecia. Uno de los temas tratados fue la asistencia personal y la necesidad de que las personas con diversidad funcional que precisaran este servicio, fueran ellas mismas las empleadoras o supervisoras de sus asistentes personales para así poder alcanzar la autodeterminación sobre su propio cuerpo y su vida (Ratzka, 2012). Aunque en un principio los representantes del movimiento de la diversidad funcional sueco se opusieron a esta idea (Ratzka, 2003, 2012), un pequeño grupo de participantes en la conferencia con necesidades de asistencia personal, continuaron reuniéndose bajo el liderazgo de Adolf Ratzka para buscar una forma de desarrollar la asistencia personal en ese país. Al año siguiente, en la primavera de 1984, este grupo formó una organización sin ánimo de lucro que denominaron Stockholmskooperativet för Independent Living (en adelante STIL), en español, Cooperativa de Estocolmo para la Vida Independiente. Durante los años siguientes esta puso en práctica un proyecto piloto de asistencia personal, con unos 20 participantes. Entre sus objetivos estaban, por un lado, permitir a las personas usuarias tener el máximo de autodeterminación y, por otro, demostrar que estas personas podían dirigir su propia asistencia personal. A finales de la década de los 80 , STIL se convirtió en una organización con una gran fuerza política; tal fue su influencia que, en el año 1993, muchos de sus reglamentos y procedimientos desarrollados durante el proyecto piloto fueron adoptados por la Agencia de la Seguridad Social (Försäkringskassan) e incorporados en el reglamento de la Ley sobre apoyos y servicios para personas con grandes discapacidades (Lagen om stöd och service till vissa funktionshindrade-LSS) (Ratzka, 2012). Así, desde enero de 1994, conseguir una vida independiente a través de la asistencia personal es un derecho de las personas con diversidad funcional en este país.

El caso español es muy diferente, ya que el derecho a la asistencia personal y a la vida independiente tiene un carácter residual en comparación con la situación en Suecia, en particular, y con otros países de la Unión 
Europea, en general. En la segunda mitad de la década de los 70 se comienza a salir de una dictadura y a democratizar todo el sistema del Estado. En los siguientes años se produce un gran desarrollo económico, social, político e institucional, surgiendo las primeras instituciones en defensa de los derechos de las personas con diversidad funcional (Erdtman, 2008). Sin embargo, no será hasta principios de la década de 2000, cuando llegue a territorio español el Movimiento de Vida Independiente (Erdtman, 2010). Concretamente, será en 2001, con la creación de la comunidad virtual denominada Foro de Vida Independiente -actualmente Foro de Vida Independiente y Divertad - cuando se comienza a divulgar y desarrollar la filosofía de este movimiento. Este foro promovió en 2003 la celebración del I Congreso Europeo sobre Vida Independiente, celebrado en Tenerife y en el que participó como ponente Adolf Ratzka y donde se aprobó el Manifiesto de Tenerife (Erdtman, 2010; Urmeneta, 2007). Gracias al activismo del foro, en los años siguientes se ponen en marcha distintos proyectos de Vida Independiente como por ejemplo las Oficinas de Vida Independiente de Madrid, Barcelona y Galicia, el programa piloto en Gipuzkoa y el de la asociación Vida Independiente de Andalucía (VIAndalucia). Asimismo, se aprueba la Ley 39/2006, de 14 de diciembre, de Promoción de la Autonomía Personal y Atención a las Personas en Situación de Dependencia, donde aparece por primera vez en nuestra normativa la figura del/la asistente personal (Arnau et al., 2007; Arnau et al., 2015; Urmeneta, 2007) y se reconoce la asistencia personal como un derecho subjetivo de las personas en situación de dependencia. Más recientemente, desde el mundo del asociacionismo tradicional, también se han puesto en marcha diferentes programas de asistencia personal, por parte de entidades como COCEMFE y PREDIF. Igualmente, esta última ha organizado el I Congreso Internacional de Asistencia Personal en España que se celebró en la ciudad de Valladolid en junio de 2017.

En síntesis, Suecia fue uno de los países de entrada del Movimiento de Vida Independiente en Europa. Desde allí se propagó por el resto de países europeos hasta llegar a España con casi dos décadas de retraso; como veremos, esta tardanza ha sido una de las causas de la gran diferencia en el desarrollo y conocimiento de este movimiento y de la asistencia personal en nuestro país.

\section{Asistencia personal: herramienta clave para la vida independiente}

\subsection{Definición de la asistencia personal}

La asistencia personal se considera una herramienta básica para que las personas con diversidad funcional y en situación de dependencia desarrollen, en igualdad de condiciones al resto de la población, una vida independiente y de calidad (Bascones et al., 2004; Matsuda et al., 2005; Rodríguez-Picavea, 2007; Young, 2003). Es un servicio de apoyo fundamental para que estas personas puedan estudiar, tener un trabajo remunerado, participar en actividades de ocio y tiempo libre, etc. (Hagglund et al., 2004). Desde el Movimiento de Vida Independiente se considera que la asistencia personal constituye un apoyo humano esencial para desarrollar la autonomía y autodeterminación de las personas con diversidad funcional (Ahlstrom y Wadensten, 2011; Arroyo y Cruz, 2015; Barrett, 2003; láñez y Aranda, 2017; Niesz et al., 2008; Turner, 2003a, 2003b; Young, 2003). De acuerdo con Nóvoa et al. (2011), la asistencia personal se caracteriza por:

- Ser un servicio de apoyo formal y regularizado mediante un contrato profesional, cuyo fin es que la persona con diversidad funcional pueda realizar las tareas de la vida diaria que por sí sola no puede 
llevar a cabo. En este sentido, la propia persona con diversidad funcional o su representante legal, es la parte contratante y la persona que ejecuta las tareas de asistencia personal es la parte contratada (Arnau et al., 2007);

- Ser una herramienta que favorece su autonomía personal, además de un instrumento básico para el empoderamiento de estas personas;

- Permitir a la persona con diversidad funcional asumir la gestión y el control de su propia vida;

- Estar reconocido como derecho humano en la Convención Internacional de los Derechos de las Personas con Discapacidad en su artículo 19 (Derecho a vivir de forma independiente y a ser incluido en la comunidad) (ONU, 2006).

\subsection{Objetivos de la asistencia personal}

Su objetivo fundamental es fomentar la autodeterminación y la vida independiente de todas las personas con diversidad funcional. Debe cubrir todas las tareas y acciones que estas personas no pueden realizar por sí mismas. En cuanto a sus objetivos específicos, debe (Gómez et al., 2015):

- Facilitar la toma de decisiones y la participación activa de estas personas;

- Prestar el apoyo necesario para llevar a cabo su propio proyecto de vida independiente;

- Aumentar la satisfacción respecto a la consecución de una vida autónoma;

- Ayudar a reducir o eliminar el estrés que se produce entre la diversidad funcional y su entorno familiar;

- Fomentar la responsabilidad de las personas con diversidad funcional en relación a este servicio;

- Evitar la institucionalización o ingresos residenciales no deseados.

\subsection{Destinatarios de la asistencia personal}

La persona destinataria de este servicio podrá ser cualquiera que tenga necesidad de apoyos, con independencia de su diversidad funcional, edad y situación económica y/o social. Este servicio debe tener un carácter universal, no debe estar condicionado por la edad, el tipo de diversidad o la actividad a realizar. Tampoco debe estar restringido a un número de horas determinado que no tenga en cuenta las necesidades, gustos y actividades expresadas por la propia persona usuaria (Moya y Sánchez Santos, 2015).

\subsection{Financiación de la asistencia personal}

En general, existen dos fuentes de financiación: las administraciones públicas y las propias personas beneficiarias y/o sus familiares. Para el Movimiento de Vida Independiente, la autogestión es fundamental para conseguir una vida autónoma y en igualdad de oportunidades, entendiendo por autogestión:

"El control por parte de la persona con diversidad funcional desde la entrevista y selección de las y los candidatos pasando por su formación, si lo requiere la situación, establecer las condiciones de trabajo, gestionar la retribución 
$\mathrm{del} / \mathrm{de}$ la asistente personal, sus obligaciones con la Seguridad Social y, si llega el caso, tener que prescindir de sus servicios" (Arnau et al., 2007: 26).

Estos trámites administrativos pueden realizarse a través de un centro de vida independiente, una cooperativa o una empresa privada. El control de la asistencia personal por parte de las propias personas con diversidad funcional no es viable si no se obtiene el económico, y esto solo es posible a través del denominado pago directo (direct payment). Siempre teniendo en cuenta que la administración que lo facilita, debe regularlo y realizar los controles que sean necesarios (Arnau et al., 2007). La fórmula de asistente personal, pago directo y derecho universal es la que facilita a las personas con diversidad funcional las herramientas básicas para tener una vida independiente de calidad y en igualdad (Rodríguez-Picavea y Romañach, 2006).

Para acceder al servicio de asistencia personal, existen dos fórmulas. Una, a través del denominado pago directo, donde es la administración correspondiente la que abona la cuantía económica directamente a la persona beneficiaria y esta se responsabiliza de los trámites de contratación, pagos de cotización, etc. y de justificación ante la administración correspondiente. Esta es la fórmula más coherente con la filosofía del Movimiento de Vida Independiente. La otra fórmula es a través de una institución que podrá ser un centro de vida independiente, cooperativa, asociación o empresa privada. La administración pública correspondiente, previo consentimiento de la persona con diversidad funcional, abona la cuantía de la prestación económica a la institución que esta haya elegido para prestar el servicio. La entidad es la que gestiona la parte administrativa del servicio y es la obligada a justificar el pago a la administración. Sin embargo, al igual que el caso anterior, es la persona con diversidad funcional la responsable de su o sus asistentes personales (Gómez et al., 2015; Socialstyrelsen, 2007, 2009; Sverige, 1993:387).

\subsection{Profesional de la asistencia personal: el/la asistente personal}

La asistencia personal se pone en práctica a través de un/a profesional: el/la asistente personal (Blanco et al., 2009; Rodríguez-Picavea, 2007). Se define como la persona que es contratada para realizar o ayudar a realizar, las actividades de la vida diaria a otra persona que por su situación, ya sea por diversidad funcional, por edad, por enfermedad... no puede realizar (Blanco et al., 2009; Oficina de Vida Independiente y Consejería de Familia y Asuntos Sociales de la Comunidad de Madrid, 2007; Rodríguez-Picavea y Romañach, 2006). La existencia del/la asistente personal se basa en el deseo y el derecho de las personas con diversidad funcional a tener el control sobre su vida y a vivirla con la dignidad que conlleva estar en igualdad de oportunidades al resto de ciudadanos. Teniendo en cuenta esto, podemos decir que la figura del/la asistente personal es una pieza muy importante del engranaje que forma la vida independiente, para una persona con diversidad funcional se traduce en algo tan sencillo y a la vez tan complicado como poder tomar decisiones, poder vivir en su domicilio, poder interactuar con su entorno, ir a trabajar, tener acceso al ocio, etc. (Rodríguez-Picavea y Romañach, 2006). Este profesional ejecuta las tareas que se acuerden en el contrato a cambio de una remuneración (Arnau et al., 2007; Rodríguez-Picavea y Romañach, 2006).

\subsubsection{Tareas del/la asistente personal}

Para cumplir su función principal, que es dar los apoyos necesarios para que todas las personas con diversidad funcional alcancen una vida activa e independiente, tienen que realizar una serie de tareas que pueden 
ser muy variadas. Las principales son ocho (Arnau et al., 2007; Oficina de Vida Independiente y Consejería de Familia y Asuntos Sociales de la Comunidad de Madrid, 2007; PREDIF, 2015; Rodríguez-Picavea y Romañach, 2006):

- Tareas personales: aseo, vestirse, levantarse de la cama, ayuda en las necesidades fisiológicas, ayuda para comer, beber, desvestirse y acostarse, preparación y toma de medicamentos, atender al teléfono, tomar notas, pasar páginas, etc.;

- Tareas del hogar: limpieza, hacer las camas, ordenar la ropa, utilizar los electrodomésticos y preparación de la comida;

- Tareas de acompañamiento: en su casa, en el trabajo, en la calle y en las actividades de ocio y tiempo libre;

- Tareas de conducción: conducir un vehículo para llevar o recoger a la persona con diversidad funcional, acompañarla a recoger a terceros, etc.;

- Interpretación: ya sea mediante la lengua de signos o por medio de diferentes ayudas técnicas;

- Coordinación: ayudar a tomar de decisiones y planificar el día a día;

- Tareas excepcionales: por ejemplo, la asistencia en estancias hospitalarias;

- Especiales: acompañamiento y/o ayuda en la preparación de las relaciones sexuales.

Se deberá realizar un estudio o evaluación de las necesidades y horas de asistencia personal para realizar una vida autónoma y en igualdad. Habrá casos en que la persona con diversidad funcional necesitará más de un/a asistente. Todos estos datos deberán quedar plasmados en un documento de valoración de las necesidades de asistencia y del proyecto de vida independiente (Oficina de Vida Independiente y Consejería de Familia y Asuntos Sociales de la Comunidad de Madrid, 2007).

\subsubsection{Delimitación profesional y requisitos del/la asistente personal}

No tenemos que olvidar que la relación entre la persona con diversidad funcional y su asistente personal está siempre regulada por un contrato legal, de no ser así, debería denominarse de otra forma, relación de amistad, de voluntariado... Su perfil profesional es muy variado, ya que está determinado por las características, las necesidades, las costumbres, los deseos y el entorno de la persona con diversidad funcional (PREDIF, 2015). A priori, cualquier persona puede trabajar como tal, sin que exista una formación específica para ello (Rodríguez-Picavea y Romañach, 2006). No obstante, lo más importante es que sepa estar y apoyar a la persona con diversidad funcional en las tareas y funciones que esta establezca. La formación que se precisa, como acabamos de señalar, dependerá de cada persona. No tendrá las mismas necesidades una persona con diversidad funcional visual que otra con dificultades auditivas (Arnau et al., 2007). Lo que sí se recomienda es una preparación en habilidades sociales que permita a los/as asistentes personales, disponer de los conocimientos suficientes para las relaciones interpersonales y poder alcanzar los objetivos señalados en el contrato, en un ambiente de respeto mutuo. También se considera necesario que tenga formación en filosofía de vida independiente para que entienda la relación con la persona con diversidad funcional y comprenda cuál es su verdadera función (Arnau et al., 2007; Oficina de Vida Independiente y 
Consejería de Familia y Asuntos Sociales de la Comunidad de Madrid, 2007). Debido a que el tipo de trabajo que realiza es de carácter muy íntimo, es de obligado cumplimiento el respeto a la privacidad y la confidencialidad. Existen unos requisitos básicos que deben cumplir todos/as los/as asistentes personales para garantizar un servicio de calidad: asumir la filosofía de vida independiente, tener una actitud de responsabilidad y compromiso, y ser mayor de 18 años (PREDIF, 2015).

Es importante no confundir este profesional con otros, por ejemplo, un auxiliar de ayuda a domicilio o con un cuidador familiar. En la tabla siguiente presentamos las principales características de la asistencia personal y otros tipos de cuidados.

\begin{tabular}{|c|c|c|}
\hline ASISTENCIA PERSONAL & CUIDADOR PROFESIONAL & CUIDADOR FAMILIAR \\
\hline La persona usuaria es el "jefe" & $\begin{array}{l}\text { El "jefe" es una empresa o servicio } \\
\text { ajeno a la persona usuaria }\end{array}$ & $\begin{array}{l}\text { Depende de la buena voluntad de la } \\
\text { persona cuidadora }\end{array}$ \\
\hline $\begin{array}{c}\text { Realiza cualquier tarea y/o función que } \\
\text { necesite la persona usuaria }\end{array}$ & $\begin{array}{l}\text { Las tareas y/o funciones que realiza } \\
\text { se reducen al ámbito domiciliario. } \\
\text { Excepcionalmente puede realizar } \\
\text { alguna tarea fuera del hogar como ir } \\
\text { a comprar o al médico }\end{array}$ & $\begin{array}{l}\text { Acuerdo tácito o implícito de qué cosas } \\
\text { se pueden pedir y cuáles no }\end{array}$ \\
\hline $\begin{array}{l}\text { Se adapta a las necesidades y } \\
\text { directrices de la persona usuaria }\end{array}$ & $\begin{array}{l}\text { No se adapta a las necesidades y } \\
\text { directrices de la persona usuaria }\end{array}$ & Dificulta la libre elección \\
\hline Es un servicio o apoyo remunerado & Es un servicio o apoyo remunerado & No está remunerado \\
\hline
\end{tabular}

Fuente: elaboración propia a partir de Xavier Urmeneta, 2011.

En resumen, los/as asistentes personales tienen una gran responsabilidad, ya que posibilitan a las personas con diversidad funcional poder elegir y realizar su propio proyecto de vida (Gómez, 2012).

\section{Panorama de la asistencia personal en Suecia y España}

\subsection{Asistencia personal en Suecia: Un derecho hecho realidad}

El año 1993 fue crucial para la política de discapacidad de este país. Se realizó la reforma de la discapacidad y se aprobaron la Ley sobre apoyo y servicios a las personas con gran discapacidad, también conocida como Ley de asistencia personal (Lagen 1993:387 om stöd och service till vissa funktionshindrade, LSS) (en adelante LSS) y la Ley de beneficios de asistencia (Lagen 1993:389 om assistansersättning, LASS) (Ratzka, 2003). Esta última, desde el año 2011, quedó derogada como ley y pasó a convertirse en el capítulo 51 del Código Social de Beneficios de Asistencia (Sveriges Riksdag, 2017). 


\subsubsection{Características de la asistencia personal}

Desde el 1 de enero de 1994, la asistencia personal es un derecho de las personas con gran diversidad funcional y uno de los diez servicios y apoyos especiales que regula la LSS. Su objetivo es garantizar a estas personas los apoyos necesarios que le permitan tener una vida digna y de calidad y a la vez, fomentar la participación en la sociedad en igualdad de oportunidades (art. 5, Lagen 1993:387).

Los requisitos para acceder son: poseer una gran diversidad funcional, necesitar un elevado nivel de apoyo para realizar las actividades básicas y tener una edad inferior a los 65 años (art. 3, Lagen 1993:389), aunque excepcionalmente se puede mantener después de cumplir esa edad (art. 9b, Lagen 1993:387). Las necesidades básicas que dan derecho a recibir la asistencia personal, son cinco: ayuda con la higiene personal, alimentación, vestido, comunicación y otros tipos de asistencia (art. 9a). En su artículo 1 se recogen los tres grupos de personas que tienen reconocido este derecho (Lagen 1993:387):

- Las personas con una diversidad funcional intelectual, autismo o similar;

- Los adultos con deterioro intelectual causado por daño cerebral;

- Otras diversidades funcionales físicas o mentales importantes y permanentes no debidas al envejecimiento normal y que originen una amplia necesidad de apoyos.

En cuanto al número de horas de asistencia, teóricamente, es ilimitado. Se pueden obtener hasta 24 horas al día, todos los días de la semana e incluso se pueden recibir otros apoyos si fueran necesarios (Socialstyrelsen, 2009). Existen dos formas de recibir asistencia personal en función de las necesidades de apoyo que tenga la persona. En el caso que la persona tenga una necesidad de ayuda inferior a 20 horas semanales (art. 10), es el municipio (administración local) el responsable de los gastos de asistencia personal (art. 9.b, Lagen 1993:387). Si la necesidad de asistencia es superior a 20 horas semanales, es responsabilidad de la Agencia de la Seguridad Social (administración nacional) (art. 3, Lagen 1993:389) (Education and Culture DG, 2006).

Para calcular la cuantía económica no se tiene en cuenta los ingresos o riqueza de la persona destinataria ni de su familia, dependerá de la necesidad de asistencia y cubrirá el $100 \%$ del costo de las horas de asistencia que se otorgue. Como ya se ha indicado, si las necesidades de apoyo son superiores a $20 \mathrm{~h} / \mathrm{semana}$ será la Agencia de la Seguridad Social la que financia la prestación económica de asistencia de acuerdo con una tarifa fija por hora de asistencia que en el año 2016 estaba fijada en $288 \mathrm{SEK} / \mathrm{h}$ (31,68 €/h aproximadamente). Existen algunos supuestos, por razones especiales, en los que el importe de la prestación de asistencia puede aumentar hasta un $12 \%$ de la cantidad estándar que en el año 2016 se estableció en 323 $\mathrm{SEK} / \mathrm{hora}(35,53 € / \mathrm{h}$ aproximadamente). La mayoría de los municipios sufragan la misma tarifa por hora que la Agencia de la Seguridad Social (Assistanskoll, 2017b).

Una vez concedidas las dietas de asistencia se puede pagar directamente a la persona beneficiaria o su tutor/a y pueden elegir entre dos opciones, contratar él mismo sus propios asistentes personales o a través de un proveedor de asistencia. Si se decide por la primera opción, no pueden contratar a ningún familiar con quién conviva (art. 9c, Lagen 1993:387), y si se opta la segunda, pueden escoger entre tres tipos de

4. 1 SEK (corona sueca) $=0,11 €($ a diciembre de 2017) 
proveedores: administración local, empresa privada o cooperativa (Socialstyrelsen, 2009). Destacar que en diciembre de 2015 estaban registrados, 1.109 proveedores privados de asistencia, entre empresas y cooperativas (Assistanskoll, 2017a; Sveriges Offiiciella Statistik, 2015).

La cantidad económica por el número de horas concedidas de asistencia, se abona mensualmente (art. 10, Lagen 1993:389).

Entre los supuestos que son incompatibles con la asistencia personal están: residir en una institución perteneciente al Estado o a una administración local; en una institución cuya gestión es subsidiada por el Estado o una administración local; o en una vivienda tutelada (art. 4, Lagen 1993:389).

\subsubsection{Coste en asistencia personal}

Según información del año 2016, el coste del Estado en asistencia personal fue de 26.300.000.000 SEK (2.893.000.000 € aproximadamente). Mientras que, en el mismo periodo, el gasto de la administración local fue de 4.800.000.000 SEK (528.000.000 € aproximadamente). Esto significa que un total de 31.100.000.000 SEK (3.421.000.000 € aproximadamente) se destinaron a financiar la asistencia personal en este país (Regeringskansliet, 2017).

\subsubsection{Número de personas beneficiarias de asistencia personal}

En septiembre de 2017, había 15.115 personas con la ayuda de la Seguridad Social (más de $20 \mathrm{~h} / \mathrm{sema-}$ nales). El 45,8\% eran mujeres y el 54,2\% hombres. Además, según datos de octubre de 2016, alrededor de 4.575 personas recibían ayuda de su municipio (menos de $20 \mathrm{~h} /$ semanales). El 45,6\% eran mujeres y el 54,1\% hombres (Assistanskoll, 2017a; Socialstyrelsen, 2015).

Si atendemos a la selección de los proveedores, las personas que recibían esta ayuda de la Seguridad Social, en diciembre de 2016, el 23,5\% habían contratado su asistencia a través del municipio, el 65,9\% lo contrató por una empresa, el 7,3\% por una cooperativa y el 3,3\% habían contratado ellos mismos sus asistentes. De aquellas que la recibían de su gobierno local, en octubre de 2015 , el $43 \%$ habían contratado su asistencia a través del municipio, el $50 \%$ lo contrató por una empresa, el $6 \%$ por una cooperativa y el $1 \%$ habían contratado ellos mismos sus asistentes (Assistanskoll, 2017a; Socialstyrelsen, 2015).

\subsubsection{Los profesionales de la asistencia personal: asistentes personales}

En 2016, había 89.400 asistentes personales, de los que 19.500 eran empleados de la administración local y 69.900 eran empleados privados (Assistanskoll, 2017b). Según el informe municipal sobre la situación laboral de los asistentes personales (Personliga assistenters arbetssituation. Fakta och debatt: Kartläggning av en ny arbetsmarknad) el 70,8 \% eran mujeres, tres de cada cuatro tenían menos de 35 años, el 33,25\% era de origen extranjero y el $19 \%$ no había nacido en Suecia. Su nivel educativo era muy variado, aunque una proporción bastante alta, el 29 \% tenía una educación universitaria (Spånt Enbuske, 2004). 
El sueldo que perciben estos profesionales depende de varios factores. Por un lado, del salario base mensual y por otro, de la capacidad individual de cada profesional. El salario base mensual varía si se trabaja para la administración local o para una entidad privada. En septiembre de 2016, los primeros tenían un sueldo base mensual de $22.600 \mathrm{SEK} / \mathrm{mes}$ (2.486 € aproximadamente), mientras que los que tenían un contrato con una entidad privada era de $22.700 \mathrm{SEK} /$ mes (2.497 $€$ aproximadamente). Independientemente de para quien trabajen, estos profesionales son evaluados anualmente por su empleador, que utiliza los llamados "factores de evaluación individuales" que son las obligaciones laborales, responsabilidades, resultados, formación y habilidades (Assistanskoll, 2017b).

En el caso de que estos trabajadores estén contratados directamente por la persona beneficiaria de la asistencia personal o en su caso, por su tutor, cobran por horas de servicio, siendo la media del salario base por hora de 136,30 SEK (14,99 € aproximadamente). Aunque estos profesionales no se acogen a ningún convenio colectivo, el empleador tiene que cumplir con la Ley de tiempo de trabajo, Ley de protección del empleo y Ley del ambiente de trabajo (Arbetstidslagen, Lagen om anställningsskydd och Arbetsmiljölagen) (Assistanskoll, 2017b).

En relación a las condiciones laborales de los asistentes personales, también dependen del convenio colectivo al que pertenezca la entidad para la que trabajen y, según este, puede variar el número de horas laborables semanales, los días festivos, el periodo vacacional, los viajes y asignaciones de contingencia, etc. (Assistanskoll, 2017b).

Por último, señalar que en Suecia todos los profesionales de la asistencia personal están representados en todos los convenios colectivos por la organización sindical Kommunal (Assistanskoll, 2017c).

\subsection{Asistencia personal en España: la gran olvidada}

La asistencia personal es de reciente implantación en la normativa española. Hasta el momento no existe ninguna ley específica que regule el derecho a la vida independiente y a la asistencia personal. Solamente desde el 2006, con la aprobación de la Ley 39/2006 de promoción de la autonomía personal y atención a las personas en situación de dependencia (en adelante LEPA), se reconoce el derecho a la asistencia personal a las personas con diversidad funcional y en situación de dependencia. Viene regulada en su artículo 19 como una prestación económica que tiene por finalidad sufragar los gastos derivados de la contratación de una asistencia personal que proporcione a la persona beneficiaria una vida autónoma, tanto en el ejercicio de las actividades básicas de la vida diaria como en el acceso al mundo laboral y/o educativo (Ley 39/2006). Destacar que la LEPA es una ley generalista con implantación en todo el territorio nacional, pero son las diferentes comunidades autónomas las responsables de aprobar las normativas que desarrollen e implemente dicha Ley en sus respectivos territorios.

\subsubsection{Características de la asistencia personal}

Las condiciones específicas de acceso a esta prestación se establecen por acuerdo del Consejo Territorial de Servicios Sociales y del Sistema para la Autonomía y Atención a la Dependencia. En términos genera- 
les, para tener derecho a recibir esta prestación se tienen que cumplir una serie de obligaciones que son comunes en todo el territorio nacional, como son: obtener el reconocimiento de persona en situación de dependencia en alguno de los grados establecidos, poseer la nacionalidad española y residir en el territorio español, al menos durante cinco años y de estos, dos deberán ser inmediatamente anteriores a la fecha de presentación de la solicitud (art. 5, Ley 39/2006) pero, además, la persona beneficiaria debe tener la capacidad necesaria para decidir qué servicios precisa, ejercer el control y dar las instrucciones necesarias a su/s asistentes personal/es y, por último, realizar un contrato laboral a su/s asistente/s personal/es, con la consiguiente alta en el régimen de la Seguridad Social correspondiente (Ley 39/2006).

Asimismo, su concesión está condicionada a la aprobación de un Programa Individual de Atención (art. 29, Ley 39/2006), en el que se debe establecer la prestación económica de asistencia personal como uno de los recursos más adecuados a las necesidades de la persona con necesidades de apoyo (Ley 39/2006).

El número de horas de asistencia depende de las necesidades individuales de la persona beneficiaria. La Ley 39/2006 no especifica cuantas deben ser, solo en su art. 19 se indica que serán las indispensable para “...que facilite al beneficiario el acceso a la educación y al trabajo, así como una vida más autónoma en el ejercicio de las actividades básicas de la vida diaria..." (Ley 39/2006: 44148).

En cuanto a la cuantía de la prestación económica, destacar que varía según el grado de dependencia reconocido y de la capacidad económica de la persona dependiente. Sin embargo, existen dos niveles de cuantías máximas que dependen de (Junta de Andalucía, 2018):

a. Si la persona beneficiaria tenía reconocido el grado de dependencia y la prestación económica antes del 1 de agosto del 2012, entonces recibe 833,96€/mes si tiene el grado III y nivel 2. En cambio, si posee el grado III y nivel 1 percibe $625,47 € /$ mes.

b. Si la persona solicitó el reconocimiento de la situación de dependencia antes del 1 de agosto del 2012 pero la resolución administrativa de dicho reconocimiento y de la prestación económica fueron posteriores a la citada fecha (en este caso también se incluyen los nuevos solicitantes), la cuantía de la prestación económica de asistencia personal es para el grado III de 715,07€/mes; para el grado II de $426,12 € /$ mes y para el grado I de $300,0 € /$ mes.

Señalar que esta prestación económica se establece como renta exenta. Esto es, una vez determinada la cuantía individual se deducen, en los supuestos en que la persona beneficiaria sea titular de cualquier otra prestación similar en otro régimen público de protección social, el importe de las siguientes prestaciones (art. 31, Ley 39/2006):

a. Complemento de gran invalidez;

b. Complemento de la asignación económica por hijo a cargo mayor de 18 años con un grado de discapacidad igual o superior a 75 por ciento;

c. Complemento por necesidad de tercera persona de la pensión de invalidez no contributiva;

d. Subsidio de ayuda a tercera persona previsto en la Ley 13/1982, de 7 de abril, de Integración Social de los Minusválidos (LISMI). 
Se abona en doce mensualidades, preferiblemente a través de transferencia bancaria a la cuenta destinada por la persona beneficiaria (Ley 39/2006).

La prestación económica de asistencia personal es incompatible con los demás servicios y prestaciones económicas, exceptuando el servicio de tele-asistencia, los servicios de prevención de las situaciones de dependencia y de promoción de la autonomía personal (art. 25 bis, Ley 39/2006).

La asistencia personal se pone en práctica a través de la figura laboral del/la asistente personal (Blanco et al., 2009; Rodríguez-Picavea, 2007) pero en nuestro país, en la actualidad, no hay una normativa estatal que regule esta profesión y la LEPA no dice nada al respecto. Un ejemplo son los requisitos que deben cumplir estos trabajadores para desempeñar su labor que una vez revisada toda la normativa de las comunidades autónomas en esta materia, son los siguientes:

- Ser mayor de 18 años;

- Residir legalmente en España;

- Proporcionar la asistencia personal mediante un contrato laboral con la persona beneficiaria -en su caso con su representante legal- o con una empresa prestadora del servicio;

- Certificar las obligaciones de afiliación y alta en el correspondiente régimen de la Seguridad Social;

- Cumplir las condiciones de idoneidad para prestar el servicio.

Para terminar este apartado, mencionar una cuestión crucial como es la formación requerida a estos profesionales. Actualmente no existe una titulación específica para ejercer esta profesión. El Acuerdo de 7 octubre de 2015, por el cual el Pleno del Consejo Territorial de Servicios Sociales y Dependencia aprobó el denominado "Sistema de acreditación en la cualificación de categorías profesionales del sistema de dependencia, que garantizará la profesionalización del sector y la calidad del empleo". En él se recogen los requisitos necesarios y la cualificación profesional de atención socio-sanitaria a personas en situación de dependencia en el domicilio para quienes realicen las funciones de asistencia personal. Obligaba, a partir del 31 de diciembre de 2017, a tener terminado un ciclo formativo de grado medio para poder trabajar de asistente personal (Resolución de 3 de noviembre de 2015). Sin embargo, esta fecha ha sido ampliada hasta el 31 de diciembre de 2022 por el Acuerdo de 19 de octubre de 2017, por el que se modifica parcialmente el Acuerdo del Consejo Territorial del Sistema para la Autonomía y Atención a la Dependencia de 27 de noviembre de 2008, sobre criterios comunes de acreditación para garantizar la calidad de los centros y servicios del Sistema para la Autonomía y Atención a la Dependencia, modificado por el Acuerdo de 7 de octubre de 2015 (Resolución de 11 de diciembre de 2017). Según este acuerdo para:

\footnotetext{
"Quienes realicen las funciones de asistencia personal a personas en situación de dependencia, previstas en el artículo 19 de la Ley 39/2006, de 14 de diciembre, de Promoción de la Autonomía Personal y Atención a las Personas en Situación de Dependencia..., deberán acreditar la cualificación profesional de atención socio-sanitaria a personas en el domicilio, establecida por el Real Decreto 295/2004, de 20 de febrero, según se determine en la normativa que la desarrolla" (Resolución de 11 de diciembre de 2017: 131077).
}

Además, en esta misma resolución se señala que: 
“...En el caso de los Asistentes Personales, las exigencias de cualificación profesional referidas anteriormente, se adaptarán a la regulación que se establezca por Acuerdo del Consejo Territorial de Servicios Sociales y del Sistema para la Autonomía Personal y Atención a las personas en situación de dependencia, que se apruebe a tal efecto" (Resolución de 11 de diciembre de 2017: 131078).

Desde el Movimiento de Vida Independiente y de los propios asistentes personales, siempre se ha demandado un nivel de cualificación profesional y un reconocimiento de esta figura, pero la aprobación de estos acuerdos entra en contradicción con los principios de este movimiento. Este considera que es la propia persona con diversidad funcional la responsable de formar a sus propios asistentes, ya que así se ajustarán a sus características, necesidades, costumbres, deseos y gustos (PREDIF, 2015).

\subsubsection{Coste en asistencia personal}

El coste de la asistencia personal en España no es una cuestión fácil de dilucidar, ya que en ella intervienen diferentes actores. La Administración General del Estado, las comunidades autónomas y las aportaciones de las personas beneficiarias son las que financian el Sistema de Autonomía y Atención a la Dependencia (en adelante SAAD) y, por consiguiente, la asistencia personal.

De acuerdo con la información aportada por el Ministerio de Hacienda y Administraciones Públicas en 2016, la Administración General del Estado presupuestó 1.252,29 millones de euros al mantenimiento del mencionado Sistema. Tras las aportaciones de las diferentes comunidades autónomas y las aportadas por las personas beneficiarias, el coste total fue de 7.986 millones de euros para el sostenimiento del SAAD (Comisión para el Análisis de la Situación del Sistema de Dependencia, 2017; Ministerio de Hacienda y Administraciones Públicas, 2015).

Para conocer el coste de la asistencia personal, solamente se puede realizar una estimación en base al número de personas beneficiarias que reciben la prestación económica de asistencia personal, por lo que se estima que en 2016 el coste de esta prestación ha sido de 28 millones de euros, lo que significa tan solo un 0,3\% del total del coste del SAAD (Comisión para el Análisis de la Situación del Sistema de Dependencia, 2017).

\subsubsection{Número de personas beneficiarias de asistencia personal}

Según datos proporcionados por el SAAD, a fecha de 30 de noviembre de 2016, 1.059 .792 personas eran beneficiarias de una o varias prestaciones o servicios. De estas tan solo 5.519 eran beneficiarias de la prestación económica de asistencia personal, eso es, un 0,52\% del total de personas beneficiarias de alguna prestación económica o servicio (IMSERSO y SAAD, 2016).

La mayoría de estas, es decir, 5.033 personas beneficiarias residían en la comunidad autónoma del País $\operatorname{Vasco}^{5}$ (7,59\%). Con una gran diferencia le seguían la Comunidad Autónoma de Castilla y León con 307

5. Algunos de los motivos por los que la gran mayoría de personas beneficiarias están en el País Vasco son: las personas mayores de 65 años también tienen derecho a la prestación económica de asistencia personal; los/as asistentes personales pueden ser contratados en el régimen especial de empleadas de hogar o como autónomos; siempre se abona la cuantía económica a la persona beneficiaria; las cuantías económicas son más altas que las estatales; es compatible con el Servicio de Ayuda a Domicilio, Centro de Atención Diurno y Centro Ocupacional y es la comunidad autónoma que más ha legislado en asistencia personal. 
$(0,28 \%)$, Galicia con $88(0,16 \%)$, la Comunidad de Madrid con $50(0,04 \%)$ y Cataluña con 14 personas beneficiarias $(0,01 \%)$. Destacar que, en cinco comunidades autónomas, las personas beneficiarias no superaban la decena y en ocho nadie recibía dicha prestación (IMSERSO y SAAD, 2016).

Por otro lado, señalar brevemente que, además de recibir asistencia personal a través de la LEPA, también se puede recibir por otras entidades que la facilita en forma de servicio. Son entidad tanto públicas como privadas: ayuntamientos, fundaciones, asociaciones, oficinas de vida independiente, confederaciones... y que no aparecen en la información proporcionada por el SAAD. Todas ellas están financiadas con dinero público, como son el Ayuntamiento de Barcelona, la Fundación ECOM, Asociación Vida Independiente de Andalucía, COGAMI, las Oficinas de Vida Independiente de la Comunidad Madrid, de Barcelona y de Galicia. Hasta donde sabemos, estas entidades prestan asistencia personal a casi 300 personas.

\subsubsection{Los profesionales de la asistencia personal: asistentes personales}

Es cierto que el interés por la asistencia personal en España ha aumentado en los últimos años, pero no es menos cierto que aún la información existente sobre este tema es insuficiente si la comparamos con otros países. Subrayar que esta escasez de información se convierte en casi inexistente si atendemos a sus profesionales.

Los asistentes personales son un grupo de trabajadores desconocidos para la mayoría de la sociedad, incluidas las administraciones, legisladores e investigadores. Hasta ahora se le ha prestado muy poca atención, no se ha legislado sobre sus condiciones de trabajo, ni sobre su ordenación jurídica y laboral. Es por ello que las dificultades en la búsqueda de informes o estudios que proporcionen conocimientos sobre el perfil de estos profesionales han sido muchas. La única información a la que hemos tenido acceso ha sido la proporcionada por el Observatorio de las Ocupaciones del Servicio Público de Empleo Estatal (en adelante SEPE). Sin embargo, hay que adelantar que en esta información y dentro de la ocupación denominada "Asistentes personales o personas de compañía" se incluyen varias actividades económicas, como: "servicios sociales sin alojamiento", "administración pública y defensa; seguridad social obligatoria", "asistencia en establecimientos residenciales", "otros servicios personales" y "actividades asociativas" (SEPE, 2016), por lo que no podemos saber con exactitud el número de asistentes personales contratados para ayudar a personas con necesidades de apoyo en sus domicilios, al no existir datos más precisos al respecto. Nos obstante, incluimos esta información porque creemos que aporta una idea global y aproximada de la realidad de estos trabajadores.

Según datos proporcionados por el citado organismo, durante el año 2016 se registraron 11.003 contratos de asistentes personales a 6.780 personas. De estos contratos, 10.547 tuvieron una duración temporal y 456 fueron indefinidos. Si atendemos al tipo de jornada laboral, 7.923 contratos fueron a tiempo parcial y 3.060 a tiempo completo. Destacar que esta profesión está fuertemente feminizada, ya que 8.713 contratos se realizaron a mujeres y 2.290 a hombres. Por grupos de edad, la mayoría de los contratos fueron realizados a personas de entre 30 y 44 años, exactamente 4.250; les siguen los contratos a personas mayores de 44 años, 3.599 y un número muy similar fueron los contratos registrados a personas de entre 18 y 29 años de edad, exactamente 3.139. Según los colectivos contratados, como acabamos ver, mayoritariamente fueron a mujeres, un $79,19 \%$ de los contratos; le siguieron las personas mayores de 45 años, 32,71 \%; los 
jóvenes, 28,64\%; las personas extranjeras, un 8,44\%; los demandantes de empleo de larga duración, un $5,42 \%$ y, por último, las personas con discapacidad con un 4,66 \% (SEPE, 2016).

En cuanto a las condiciones laborales de estos trabajadores, destacar que también es un dato difícil de conocer, al no existir una regulación estatal, ni convenio colectivo que regule esta figura laboral. En la actualidad, existen dos formas de ser contratados dentro de la LEPA (PREDIF, 2015):

- Por una empresa, cooperativa u oficina de vida independiente que facilitan los asistentes personales a la persona con necesidades de apoyo. Estas son las responsables de cumplir todas las obligaciones con la administración (alta en la SS.SS., cotizaciones, etc.). Los asistentes personales son contratados por cuenta ajena y dados de alta en el Régimen General de la Seguridad Social.

- Por la propia persona con necesidades de apoyo o por su tutor/a legal. Se les realiza un contrato por cuenta propia, dándose de alta en la Seguridad Social, en el Régimen Especial de Trabajadores Autónomos (RETA) y son ellos los responsables de cumplir todas las obligaciones de alta, cotizaciones a la SS.SS., etc.

Esta última modalidad es la que más dificultades presenta en nuestro país, desde el punto de vista económico y administrativo. Por un lado, es la forma menos rentable para los asistentes personales ya que a su salario (importe de la prestación económica) hay que descontarle la cuota de autónomos. Por otro, al no existir ninguna norma estatal que regule esta figura laboral, no hay fórmulas administrativas para la autogestión que superen todas las trabas burocráticas para el pago directo. En otros países como en Suecia, existe el pago directo para que la persona beneficiaria contrate directamente a sus propios asistentes personales. En cambio, en España la LEPA no contempla esta opción, dado que en su artículo 19 dice: “...su objetivo es contribuir a la contratación de una asistencia personal..." esto es, un servicio de asistencia personal y no un/a asistente personal (PREDIF, 2015). Mientras esta situación no cambie y se siga considerando a las personas con necesidades de apoyo o en situación de dependencia como receptoras y no como empleadoras, será difícil que estas tengan un completo control sobre sus asistentes personales y su propia vida.

A modo de resumen, en la siguiente tabla se presenta toda la información sobre la asistencia personal en los dos países estudiados; los datos corresponden al año 2016: 


\begin{tabular}{|c|c|c|}
\hline & SUECIA & ESPAÑA \\
\hline LEGISLACIÓN & \begin{tabular}{|l|} 
- Lagen 1993:387 om stöd och service till \\
vissa funktionshindrade, LSS (Ley sobre \\
Apoyo y Servicios a las Personas con gran \\
Discapacidad, también conocida como Ley \\
de Asistencia Personal). \\
- Lagen 1993:389 om assistansersättning, \\
LASS (Ley de Beneficios de Asistencia). \\
\end{tabular} & $\begin{array}{l}\text { Ley 39/2006 de Promoción de la Autonomía Personal y } \\
\text { Atención a las Personas en Situación de Dependencia. }\end{array}$ \\
\hline $\begin{array}{l}\text { AÑO DE ENTRADA EN } \\
\text { VIGOR } \\
\end{array}$ & 1994 & 2007 \\
\hline OBJETIVO & $\begin{array}{l}\text { Garantizar los apoyos necesarios que le } \\
\text { permitan tener una vida digna y de calidad y a } \\
\text { la vez, fomentar la participación en la sociedad } \\
\text { en igualdad de oportunidades. }\end{array}$ & $\begin{array}{l}\text { Sufragar los gastos derivados de la contratación de } \\
\text { una asistencia personal que proporcione a la persona } \\
\text { beneficiaria una vida autónoma, tanto en el ejercicio } \\
\text { de las actividades básicas de la vida diaria como en el } \\
\text { acceso al mundo laboral y/o educativo. }\end{array}$ \\
\hline $\begin{array}{l}\text { REQUISITOS PARA } \\
\text { TENER DERECHO }\end{array}$ & $\begin{array}{l}\text { - Tener una gran diversidad funcional. } \\
\text { - Necesitar un elevado nivel de apoyo para } \\
\text { realizar las actividades básicas de la vida } \\
\text { diaria. } \\
\text { - Ser menor de } 65 \text { años. }\end{array}$ & $\begin{array}{l}\text { - Reconocimiento de la situación de persona } \\
\text { dependiente en cualquiera de sus grados. } \\
\text { - Poseer la nacionalidad española. } \\
\text { - Residir en el territorio español, al menos } \\
\text { durante cinco años y de estos, dos deberán ser } \\
\text { inmediatamente anteriores a la fecha de presentación } \\
\text { de la solicitud. }\end{array}$ \\
\hline $\begin{array}{l}\text { MÁXIMO DE HORAS } \\
\text { DE APOYO }\end{array}$ & Ilimitado. & No especificado \\
\hline $\begin{array}{l}\text { CÁLCULO DE LA } \\
\text { CUANTÍA ECONÓMICA }\end{array}$ & $\begin{array}{l}\text { - No se tiene en cuenta los ingresos o riqueza } \\
\text { de la persona destinataria ni de su familia. } \\
\text { - Depende de la necesidad de asistencia. } \\
\text { - Cubre el } 100 \% \text { del costo de las horas de } \\
\text { asistencia. }\end{array}$ & $\begin{array}{l}\text { Depende de: } \\
\text { - El grado de dependencia reconocido. } \\
\text { - La capacidad económica de la persona dependiente. }\end{array}$ \\
\hline CUANTÍA ECONÓMICA & $\begin{array}{l}288 \mathrm{SEK} / \mathrm{h}(30,99 € / \mathrm{h} \text { aproximadamente) } \\
\text { por razones especiales se incrementa hasta } \\
\text { un } 12 \% \text {, siendo } 323 \mathrm{SEK} / \mathrm{hora}(34,75 € / \mathrm{h} \\
\text { aproximadamente). }\end{array}$ & $\begin{array}{l}\text { Si la persona beneficiaria tuviera reconocido el grado de } \\
\text { dependencia y la prestación antes de la entrada julio del } \\
2012 \text { de } 13 \text { de julio, la cuantía es: } \\
\text { - Grado III, nivel } 2: 833,96 € / m e s \\
\text { - Grado III, nivel 1: } 625,47 € / m e s \\
\text { Si la persona beneficiaria hubiese adquirido este derecho } \\
\text { después de la entrada en vigor de la fecha mencionada, } \\
\text { será: } \\
\text { - Grado III: } 715,07 € / \text { mes } \\
\text { - Grado II: } 426,12 € / \text { mes } \\
\text { - Grado I: } 300,00 € / \text { mes }\end{array}$ \\
\hline INCOMPATIBILIDADES & $\begin{array}{l}\text { Residir en: } \\
\text { - Una institución perteneciente al Estado o a } \\
\text { - } \text { una administración local. } \\
\text { es una institución cuya gestión } \\
\text { administración por el Estado o una } \\
\text { - En una vivienda tutelada. } \\
\end{array}$ & $\begin{array}{l}\text { Las prestaciones económicas serán incompatibles entre } \\
\text { sí, salvo con el servicio de teleasistencia, los servicios } \\
\text { de prevención de las situaciones de dependencia y de } \\
\text { promoción de la autonomía personal. }\end{array}$ \\
\hline $\begin{array}{l}\text { COSTE DE LA } \\
\text { ASISTENCIA } \\
\text { PERSONAL }\end{array}$ & $\begin{array}{l}31.100 .000 .000 \text { SEK }(3.421 .000 .000 € \\
\text { aproximadamente) }\end{array}$ & $28.000 .000 €$ \\
\hline $\begin{array}{l}\text { NÚMERO DE } \\
\text { PERSONAS } \\
\text { BENEFICIARIAS } \\
\end{array}$ & 19.690 & 5.519 \\
\hline
\end{tabular}




\begin{tabular}{|c|c|c|}
\hline & SUECIA & ESPAÑA \\
\hline $\begin{array}{l}\text { NÚMERO DE } \\
\text { ASISTENTES } \\
\text { PERSONALES }\end{array}$ & 89.400 & 6.780 \\
\hline $\begin{array}{l}\text { SUELDO DE LOS } \\
\text { ASISTENTES } \\
\text { PERSONALES }\end{array}$ & $\begin{array}{l}\text { Entre } 22.600 \mathrm{SEK} / \mathrm{mes}(2.316,27 € / \mathrm{mes}) \text { y } \\
22.700 \mathrm{SEK} / \mathrm{mes}(2.326,52 € / \mathrm{mes}) \text { de sueldo } \\
\text { base. }\end{array}$ & Entre $833,96 € /$ mes y $300,00 € /$ mes. \\
\hline $\begin{array}{l}\text { FORMACIÓN DE } \\
\text { LOS ASISTENTES } \\
\text { PERSONALES }\end{array}$ & No hay ninguna concreta. & No hay ninguna concreta. \\
\hline
\end{tabular}

Fuente: elaboración propia.

\section{Conclusiones}

Es importante destacar que ambos países aprobaron y ratificaron la Convención Internacional de los Derechos de las Personas con Discapacidad, por lo que el derecho de estas personas a vivir de forma independiente y a ser incluidas en la comunidad, a través de una asistencia personal de calidad forma parte su ordenamiento jurídico. Todas las administraciones públicas están obligadas a garantizarlo, por lo que deberán elaborar, aprobar e implementar las medidas necesarias para hacerlo realidad. En el caso de Suecia existe una larga tradición en garantizar este derecho a diferencia de España donde su puesta en práctica parece no ejecutarse, ya sea por falta de legislación específica que la desarrolle e implemente en cada comunidad autónoma, por falta de presupuesto económico o, en el peor de los casos, por falta de voluntad política (López Pérez, 2012), quedando aún mucho camino por recorrer.

Solamente en Suecia se ha aprobado una legislación específica que regula la asistencia personal para todos los ámbitos de la vida. Sin embargo, en nuestro país, está regulada por una ley generalista en el tema de la dependencia y solamente se prevé este recurso para ayudar a las actividades básicas de la vida diaria y el acceso al empleo $\mathrm{y}$ al estudio de las personas con diversidad funcional.

Indicar que la cuantía económica de esta prestación, en la legislación sueca, se calcula por hora necesaria de asistencia a diferencia de la española que es un importe fijo según algunos parámetros como es el grado de dependencia, pero obviando el número de horas necesarias de asistencia para cubrir las necesidades de estas personas.

Destacar que en España es una necesidad imperante que la figura profesional del asistente personal sea regulada, diferenciándola claramente de otras como auxiliares de ayuda a domicilio, asistentas del hogar o cuidadores informales. También que se apruebe un convenio especifico que establezca las condiciones laborales de estos trabajadores y que se incluyan en el Régimen General de cotización a la Seguridad Social.

Subrayar la cuestión del acceso a la información en torno a la asistencia personal. En el caso de Suecia, existe la web Assistanskoll que recoge todo lo relacionado con este servicio en el país, desde artículos sobre el tema, datos estadísticos, cuantía de la prestación, proveedores, bolsa de trabajo para asistentes personales, salario de estos profesionales, etc. Por el contrario, en el caso español, la falta de información o datos estadísticos sobre la 
asistencia personal es una característica. Por ejemplo, se desconoce qué características tienen las personas que reciben esta prestación (edad, sexo, estudios, situación laboral...), cómo gestionan su asistencia (auto-gestionada o a través de un proveedor), número de proveedores de este servicio, etc. Todas estas peculiaridades dificultan conocer y comparar en profundidad este servicio en ambos países.

En síntesis, si se quiere crear una sociedad más justa, igualitaria y respetuosa, es ineludible que la inclusión y la participación de las personas con diversidad funcional en la misma sea un derecho real, y para conseguirlo es necesario que confluyan diversos factores y, entre ellos, la asistencia personal es básica e indispensable. 


\section{Referencias bibliográficas}

Aguado, A.L. (1995): Historia de las deficiencias. Madrid: Escuela Libre Editorial.

Ahlstrom, G. y Wadensten, B. (2011): "Family members' experiences of personal assistance given to a relative with disabilities". Health \& Social Care in the Community, 19 (6): 645-652.

Arnau, S. (2013): "La Filosofía de Vida Independiente. Una estrategia política noviolenta para una cultura de paz". Revista Latinoamericana de Educación Inclusiva, 7 (1): 93-112.

Arnau, S. (2006): "Ley de la "In-Dependencia": pasos necesarios para garantizar un nuevo Derecho de Ciudadanía". Lan harremanak: Revista de relaciones laborales, 15: 41-64.

Arnau, S. (2002): "Una construcción social de la discapacidad: el Movimiento de Vida Independiente". Fòrum de Recerca, 8: 1-11.

Arnau, S. et al. (2015): La Asistencia Personal. Características y acciones a tomar para su implantación (en línea). <http://forovidaindependiente.org/la-asistencia-personal-caracteristicas-y-acciones-a-tomar-para-suimplantacion/>, acceso 17 de julio de 2017.

Arnau, S. et al. (2007): Asistencia personal para la vida independiente y la promoción de la autonomía de las personas con diversidad funcional (discapacidad) en España (en línea). <www.faeba.es/descargar.php?id=5>, acceso 4 de septiembre de 2017.

Arroyo, J. y Cruz, E. (2015): “La asistencia personal”, en Ortega Alonso, E. (coord.): Situación de la Asistencia Personal en España. Madrid: PREDIF.

Assistanskoll (2017a): Statistik om personlig assistans (en línea). <https://assistanskoll.se/assistans-statistik.php>, acceso 14 de noviembre de 2017.

Assistanskoll (2017b): Vad har personliga assistenter i lön? (en línea). <https://assistanskoll.se/Guider-om-personliga-assistenters-loner.html>, acceso 12 de noviembre de 2017.

Assistanskoll (2017c): Kollektivavtal och anställningsvillkor i personlig assistans (en línea). <https://assistanskoll. se/20080319-FAKTA-kollektivavtal.html>, acceso 3 de noviembre de 2017.

Barrett, J. C. (2003): "Being an effective workplace Personal Assistant". Journal of Vocational Rehabilitation, 18 (2): $93-97$.

Bascones, L. M. et al. (2004): Ideas para una vida activa en igualdad de oportunidades. El futuro de la "inDependencia" (en línea). <http://www.asoc-ies.org/vidaindepen/docs/ideas_vidactiva_fvi.pdf>, acceso 10 de mayo de 2017.

Blanco, M. et al. (2009): Asistencia personal: una inversión en derechos; una inversión eficiente en empleo (en línea). <http://www.vigalicia.org/files/documentos/asistencia_personal_empleo_derecho_preval.pdf>, acceso 11 de septiembre de 2017.

Boyle, G. (2008): “Autonomy in long-term care: a need, a right or a luxury?” Disability and Society, 23 (4): $299-310$.

Campo, M. (2005): "Orígenes e historia del Movimiento de Vida Independiente. Vida Independiente en la Universidad”. En I Jornada de Vida Independiente. Donostia: Diputación Foral de Gipuzkoa. 
Centeno, A. et al. (2008): "Indicadores de Vida Independiente (IVI) para la evaluación de políticas y acciones desarrolladas bajo la Filosofía de Vida Independiente" (en línea). <http://www.minusval2000.com/pdf/Indicadores_de_Vida_Independiente.pdf>, acceso 14 septiembre de 2017.

Comisión para el análisis de la situación del Sistema de Dependencia (2017): Informe de la Comisión para el análisis de la situación actual del sistema de la dependencia, de su sostenibilidad y de los actuales mecanismos de financiación (en línea). <http://www.dependencia.imserso.es/InterPresent2/groups/imserso/documents/binario/inf_comision_analisis_20171006.pdf>, acceso 3 de octubre de 2017.

Comité Español de Representantes de Personas con Discapacidad (CERMI) (2003): Discapacidad y exclusión social en la Unión Europea. Tiempo de cambio, herramientas para el cambio (en línea). <http://www.cermiasturias.org/fotos/7Exclusion.pdf>, acceso 20 de junio de 2017.

Deegan, P. E. (1992): "The Independent Living Movement and people with psychiatric disabilities: taking back control over our own lives". Psychosocial Rehabilitation Journal, 15 (3): 3-19.

Dejong, G. (1979a): "The Movement for Independent Living: origins, ideology and implications for disability research". University Centers for International Rehabilitation, Michigan: Michigan State University.

Dejong, G. (1979b): "Independent living: from social movement to analytic paradigm". Archives of physical medicine and rehabilitation, 60: 435-446.

Doyal, L. y Gough, I. (1991): A theory of human need. New York: Guilford Press.

Education and Culture DG (2006): Sweden care work with people with disabilities. Lifelong Learning Programme "Leonardo da Vinci".

Erdtman, E. (2010): Spain-Assistance-available in Spain by law, but not in reality (en línea). <http://www.independentliving.org/docs7/Spain-personal-assistance-not-reality.html>, acceso 24 de junio de 2017.

Erdtman, E. (2008): Spain-spaniards are fighting for more personal assistance (en línea). <http://www.independentliving.org/docs7/Spain-personal-assistance.html>, 26 de junio de 2017.

España. Resolución de 11 de diciembre de 2017, de la Secretaría de Estado de Servicios Sociales e Igualdad, por la que se publica el Acuerdo del Consejo Territorial de Servicios Sociales y del Sistema para la Autonomía y Atención a la Dependencia, que modifica parcialmente el Acuerdo de 27 de noviembre de 2008, sobre criterios comunes de acreditación para garantizar la calidad de los centros y servicios del Sistema para la Autonomía y Atención a la Dependencia. Boletín Oficial del Estado, 30 de diciembre de 2017, núm. 317, pp. 131075-131081.

España. Resolución de 3 de noviembre de 2015, de la Secretaría de Estado de Servicios Sociales e Igualdad, por la que se publica el Acuerdo del Consejo Territorial de Servicios Sociales y del Sistema para la Autonomía y Atención a la Dependencia, que modifica parcialmente el Acuerdo de 27 de noviembre de 2008, sobre acreditación de centros y servicios del Sistema para la Autonomía y Atención a la Dependencia. Boletín Oficial del Estado, 16 de noviembre de 2015, núm. 274, pp. 107884 a 107888.

España. Ley 39/2006, de 14 de diciembre, de Promoción de la Autonomía Personal y Atención a las Personas en Situación de Dependencia. Boletín Oficial del Estado, núm. 299, 15 de diciembre de 2006, pp. 44142-44156.

Evans, J. (1998): Shaping our futures, a conference on independent living (en línea). <http://www.independentliving.org/docs2/enilfuture.html>, acceso 11 de julio de 2017.

García Alonso, J. V. (coord.) (2003): El Movimiento de Vida Independiente. Experiencias internacionales. Madrid: Fundación Luis Vives. 
Gillinson, S. et al. (2005): Independent Living. The right to be equal citizens. London: Demos.

Gómez, N. (2012): “Vida Independiente: Instrumentos para garantizar el cambio de paradigma”, en Pié Balaguer, A. (coord.): Deconstruyendo la dependencia: propuesta para una vida independiente. Barcelona: Editorial UOC.

Gómez, N. et al. (2015): Prestación del servicio de asistencia personal, en Ortega Alonso, E. (coord.): Situación de la Asistencia Personal en España. Madrid, España: PREDIF.

Hagglund, K. J. et al. (2004): "The current state of personal assistance services: implications for policy and future research". NeuroRehabilitation, 19 (2): 115-120.

Hyung Shik, K. (2010): "UN Disability Rights Convention and implications for social work practice". Australian Social Work, 63 (1): 103-116.

láñez, A. (2009): "Vida independiente y diversidad funcional. Resultados de una investigación social aplicada en la provincia de Sevilla". Portularia IX (1): 93-103.

láñez, A. y Aranda, J.L. (2017): Impacto económico y social del Proyecto de Asistencia Personal de VIAndalucia. Sevilla: Diversitas Ediciones.

Instituto de Mayores y Servicios Sociales (IMSERSO) y Sistema para la Autonomía y Atención a la Dependencia (SAAD) (2016): Información estadística del Sistema para la Autonomía y Atención a la Dependencia. Situación a 30 de noviembre de 2016. Recuperado de http://www.dependencia.imserso.gob.es/InterPresent1/groups/ imserso/documents/binario/estsisaad20161130.pdf

Junta de Andalucía (2018): Determinación de cuantías (en línea). <http://www.juntadeandalucia.es/organismos/ igualdadypoliticassociales/areas/dependencia/prestaciones/paginas/asistencia-personal.html>, acceso 14 de junio de 2017.

Lobato, M. (2005): "Filosofía del Movimiento de Vida Independiente. El concepto de Asistencia Personal”. En I Jornada de Vida Independiente. Donostia: Diputación Foral de Gipuzkoa.

López Pérez, M. (2012): "Prestación económica de asistencia personal: asignatura pendiente de la Ley 39/2006, de 14 de diciembre". Portularia, XII (nº extra): 111-120.

Madrid, A. (2013): "Nothing about us without us! El Movimiento de Vida Independiente: comprensión, acción y transformación democrática". Oxímora Revista Internacional de Ética y Política, 2: 22-38.

Maraña, J.J. y Lobato, M. (2003): “El Movimiento de Vida Independiente en España”, en García Alonso, J.V. (coord.): El Movimiento de Vida Independiente. Experiencias internacionales. Madrid: Fundación Luis Vives.

Maraña, J.J. y Ratzka, A. (1999): Vida Independiente. Buenas prácticas. Madrid: IMSERSO.

Maslow, A. H. (1943): “A Theory of Human Motivation”. Psychological Review, 50 (4): 370-396.

Matsuda, S. J. et al. (2005): "Barriers and satisfaction associated with personal assistance services: results of consumer and personal assistant focus groups". OTJR: Occupation, Participation and Health, 25 (2): 66-74.

Ministerio de Hacienda y Administraciones Públicas (2015): Presentación del Proyecto de presupuestos generales del Estado 2016 (en línea). <http://www.sepg.pap.minhafp.gob.es/sitios/sepg/es-ES/Presupuestos/PresupuestosEjerciciosAnteriores/Documents/EJERCICIO\%202016/LIBROAMARILLO2016.pdf>, acceso 8 de octubre de 2017.

Morris, J. (1993): Independent Lives? Community care and disabled people. Basingstoke: Macmillans. 
Moya, M. J. y Sánchez Santos, F. (2015): "La persona con diversidad funcional como beneficiario”, en Ortega Alonso, E. (coord.): Situación de la Asistencia Personal en España. Madrid: PREDIF.

Niesz, T. et al. (2008): "The empowerment of people with disabilities through qualitative research". Work: A Journal Prevention, Assessment and Rehabilitation, 31 (1): 113-125.

Nóvoa, J. A. (2003): Aproximación al modelo de Centro de Vida Independiente en los Estados Unidos de Norteamérica (en línea). <http://forovidaindependiente.org/aproximacion-al-modelo-de-centro-de-vida-independiente-en-los-estados-unidos-de-norteamerica/>, acceso 2 de agosto de 2017.

Nóvoa, J. A. et al. (2011): La asistencia personal. Un recurso económicamente eficiente, socialmente y humanamente deseable, y excelente en el empleo (en línea). <http://forovidaindependiente.org/la-asistencia-personalun-recurso-economicamente-eficiente-social-y-humanamente-deseable-y-excelente-en-el-empleo/>, acceso 12 de julio de 2017.

Oficina de Vida Independiente y Consejería de Familia y Asuntos Sociales de la Comunidad de Madrid (2007): Guía Práctica de la Asistencia Personal (en línea). <http://www.madrid.org/bvirtual/BVCM013822.pdf>, acceso 31 de mayo de 2017.

Organización de las Naciones Unidas (ONU) (2017): Observación general núm. 5 (2017) sobre el derecho a vivir de forma independiente y a ser incluido en la comunidad.

Organización de las Naciones Unidas (ONU) (2006): Convención Internacional sobre los derechos de las personas con Discapacidad (en línea). <http://sid.usal.es/idocs/F3/LYN10244/3-10244.pdf>, acceso 3 de abril de 2017.

Organización Mundial de la Salud (OMS) (2001): Clasificación Internacional del Funcionamiento, de la Discapacidad y de la Salud. Ginebra: Ediciones de la OMS.

Organización Mundial de la Salud (OMS) (1980): Clasificación Internacional de Deficiencias, Discapacidades y Minusvalías. Ginebra: Ediciones de la OMS.

Palacios, A. y Romañach, J. (2006): El modelo de la diversidad. La bioética y los derechos humanos como herramientas para alcanzar la plena dignidad en la diversidad funcional. Santiago de Compostela: Ediciones Diversitas-AIES.

Planella, J. et al. (2012): "Activismo y lucha encarnada por los derechos de las personas con dependencia en España: 1960-2010”. Intersticios. Revista Sociológica de Pensamiento Crítico, 6 (2): 49-61.

Plataforma Representativa Estatal de Personas con Discapacidad Física (PREDIF) (2015): Situación de la Asistencia Personal en España (en línea). <http://www.predif.org/sites/default/files/documents/ASISTENCIA\%20 PERSONAL.pdf $>$, acceso 17 de abril de 2017.

Power, A. (2013): "Understanding the complex negotiations in fulfilling the right to independent living for disabled people". Disability \& Society, 28 (2): 204-217.

Ratzka, A. (2012): The independent living movement paved the way: Origins of personal assistence in Sweden. Perspectives on personal assistance (en línea). <https://www.independentliving.org/docs7/Independent-Living-movement-paved-way.html>, acceso 27 de abril de 2017.

Ratzka, A. (2003): Independent Living in Sweden (en línea). <http://www.independentliving.org/docs/Independent_ Living_in_Sweden.html\#1994>, acceso 20 de mayo de 2017. 
Regeringskansliet (2017): Budgetpropositionen för 2018 (en línea). <http://www.regeringen.se/rattsdokument/proposition/2017/09/prop.-2017181/>, acceso24 de octubre de 2017.

Rodríguez-Picavea, A. (2010): "Vida Independiente: Dignidad y derechos de la diversidad funcional. Revista de Terapia Ocupacional Galicia, 7 (6): 78-101.

Rodríguez-Picavea, A. (2007): "Reflexiones en torno a la figura del asistente personal para la vida independiente y la promoción de la autonomía de las personas con diversidad funcional (discapacidad)". Zerbitzuan, 41: 115127.

Rodríguez-Picavea, A. y Romañach, J. (2006): Consideraciones sobre la figura del Asistente Personal en el Proyecto de Ley de Promoción de la Autonomía Personal y Atención a las Personas en Situación de Dependencia (en línea). <http://www.carm.es/ctra/cendoc/haddock/14123.pdf>, acceso 5 de mayo de 2017.

Romañach, J. y Lobato, M. (2005): Diversidad funcional. Un nuevo término para la lucha por la dignidad en la diversidad del ser humano (en línea). <http://forovidaindependiente.org/wp-content/uploads/diversidad_funcional. pdf $>$, acceso 30 de junio de 2017.

Servicio Público de Empleo Estatal (SEPE) (2016): Información Anual de Mercado de Trabajo por Ocupación (en línea). <https://www.sepe.es/contenidos/observatorio/ocupaciones/ultimo_anual/ESTUDIO_OCUPACIONES_A. pdf>, acceso 19 de octubre de 2017.

Socialstyrelsen (2015): Kartläggning och analys av vissa insatser enligt LSS Tilläggsuppdrag avseende insatsen personlig assistans (en línea). <https://assistanskoll.se/_up/Socialstyrelsen-Kartlaggning-analys-september-2015. pdf>, acceso 27 de septiembre de 2017.

Socialstyrelsen (2009): Swedish disability policy-service and care for people with functional impairments (en línea). <http://www.socialstyrelsen.se/Lists/Artikelkatalog/Attachments/8407/2009-126-188_2009126188.pdf>, acceso 1 de septiembre de 2017.

Socialstyrelsen (2007): Lag om stöd och service till vissa funktionshindrade - LSS (en línea). <http://www.socialstyrelsen.se/Lists/Artikelkatalog/Attachments/9083/2007-114-49_200711429.pdf>, acceso 23 de septiembre de 2017.

Spånt Enbuske, A. (2004): Personliga assistenters arbetssituation. Fakta och debatt: Kartläggning av en ny arbets. Stockholm: Kommunal.

Sverige. Lagen 1993:387 om stöd och service till vissa funktionshindrade (LSS). Regeringskansliet, 25 de mayo de 1993, 387, pp. 311-319.

Sverige. Lagen 1993:389 om assistansersättning (LASS). Regeringskansliet, 25 de mayo de 1993, 389.

Sveriges Offiiciella Statistik (Socialtjänst) (2015): Personer med funktionsnedsättning-insatser enligt LSS år 2014 (en línea). <http://www.socialstyrelsen.se/Lists/Artikelkatalog/Attachments/19786/2015-3-34.pdf>, acceso 10 de octubre de 2017

Sveriges Riksdag (2017): Socialförsäkringsbalk 2010:110 (en línea). <http://www.riksdagen.se/sv/dokument-lagar/ dokument/svensk-forfattningssamling/socialforsakringsbalk-2010110_sfs-2010-110>, acceso 14 de septiembre de 2017.

Toboso, M. (2010): “Juventud y derechos humanos en el respeto a la diversidad funcional”. Revista de Estudios de Juventud, (89): 201-219. 
Turner, E. (2003a): “Finding the right Personal Assistant”. Journal of Vocational Rehabilitation, 18 (2): 87-91.

Turner, E. (2003b): “Using a Personal Assistant in the workplace”. Journal of Vocational Rehabilitation 18 (2): $81-85$.

Urmeneta, X. (2011): Vida Independiente y Asistencia Personal. La experiencia de Gipuzkoa (en línea). <http:// docplayer.es/8367964-Vida-independiente-y-asistencia-personal-la-experiencia-de-gipuzkoa.html>, acceso 31 de mayo de 2017.

Urmeneta, X. (2007): “La vida independiente en Gipuzkoa: Una alternativa para las personas con discapacidad y dependencia”. Zerbitzuan, (42): 87-92.

White, G. W. et al. (2010): "Moving from independence to interdependence: A conceptual model for better understanding community participation of centers for independent living consumers". Journal of Disability Policy Studies, 20 (4): 233-240.

Young, A. J. (2003): "The evolution of personal assistant services as a workplace support". Journal of Vocational Rehabilitation, 18 (2) 73-80.

Zarb, G. (2003): “Vida Independiente: visión económica”, en García Alonso J. V. (coord.): El Movimiento de Vida Independiente. Experiencias internacionales. Madrid: Fundación Luis Vives.

Zarb, G. y Nadash, P. (1994): Cashing in on independence. Comparing the costs and benefits of cash \& services. Derbyshire: The British Council of Organisations of Disabled People Publication. 